\title{
Platypnea-orthodeoxia syndrome combined with constrictive pericarditis after coronary artery bypass surgery
}

Masaki Hashimoto, MD, PhD, Yasuhide Okawa, MD, Hiroshi Baba, MD,

Yoshiyuki Nishimura, MD, and Masakazu Aoki, MD, Toyohashi, Japan

\section{Clinical Summary}

A 61-year-old man presented with dyspnea 3 years after coronary artery bypass surgery. He had multiple cerebral infarctions 1 year after the operation. Because pulse oximetry was $92 \%$ in room air at his physician's consultation, he started home oxygen therapy. After 3 years, his dyspnea got worse. Redo work-up, including ventilation/perfusion (V/Q) scanning and computed tomographic scanning, was done. The result of the V/Q scan was normal. Computed tomographic scanning showed an abnormal cyst above the heart. The cyst contained liquid and showed a compressed right atrium and right ventricular outflow (Figure 1). He consulted with our institution to perform an extensive work-up.

Physical examination revealed a regular pulse, a blood pressure of 103/81 mm Hg, and no murmur in cardiac auscultation. Arterial blood gas analysis in a sitting posture showed a $\mathrm{PaO}_{2}$ of $53.8 \mathrm{~mm}$ $\mathrm{Hg}$ and a $\mathrm{PaCO}_{2}$ of $24.6 \mathrm{~mm} \mathrm{Hg}$ with $15 \mathrm{~L}$ of oxygen supplementation by means of a face mask and $\mathrm{a} \mathrm{PaO}_{2}$ of $63.2 \mathrm{~mm} \mathrm{Hg}$ and a $\mathrm{PaCO}_{2}$ of $25.1 \mathrm{~mm} \mathrm{Hg}$ in the supine position. Common blood count showed polycythemia, with a hematocrit value of $52.4 \%$. Chest radiographic film showed any apparent pulmonary disease that could be a cause of the dyspnea.

Electrocardiography revealed sinus rhythm and left atrial load. Echocardiography was performed and revealed right atrial compression. Transesophageal echocardiography revealed an atrial septal aneurysm and patent foramen ovale and a right-to-left shunt through the foramen ovale. These shunts increased in a sitting posture.

Cardiac catheterization was performed and revealed a small right-to-left shunt (27.3\%). A small portion of blood flowed from the superior vena cava influx directly into the inferior vena cava. Blood flowed from the inferior vena cava influx into the left atrium through the foramen ovale. The previous bypass graft (ie, the left internal thoracic artery to the left anterior descending artery) was patent. All of the right-sided intracardiac pressure measurements were normal (Table 1).

From the Division of Cardiovascular Surgery, Toyohashi Heart Center, Toyohashi, Aichi, Japan.

Received for publication May 24, 2006; revisions received June 21, 2006; accepted for publication July 12, 2006

Address for reprints: Masaki Hashimoto, MD, PhD, Division of Cardiovascular Surgery, Toyohashi Heart Center, 21-1 Gobudori, Oyama-cho, Toyohashi, 4418530, Japan (E-mail: hashimoto@ heart-center.or.jp).

J Thorac Cardiovasc Surg 2006;132:1225-6

$0022-5223 / \$ 32.00$

Copyright $\odot 2006$ by The American Association for Thoracic Surgery

doi:10.1016/j.jtcvs.2006.07.021
Surgical removal of the cyst was performed. There were polytetrafluoroethylene* sheets surrounding the heart. There was a cyst surrounding the right atrium from the right side of the left atrium to the right ventricle. The cyst had a thick scar tissue and contained $300 \mathrm{~mL}$ of old, black serous liquid. Just after opening the cyst, the pulse oximetry improved, from $79 \%$ to $100 \%$. The right atriotomy was performed during ventricular fibrillation with cardiopulmonary bypass. There was a patent foramen ovale, and the slit was closed in a continuous fashion. Because the right ventricle was covered with thick pericardium and expressed constrictive pericarditis, a complete pericardiectomy was performed.

The postoperative course was uneventful, and weaning from mechanical ventilation was quite easy. The patient could be withdrawn from oxygen supplementation and was discharged on postoperative day 15 .

\section{Discussion}

Platypnea-orthodeoxia syndrome is infrequent, and the diagnosis can be difficult. Cheng ${ }^{1}$ points out that two conditions must coexist to cause this syndrome. One is an anatomic component in the form of an interarterial communication, and the other is a functional component that produces a deformity in the atrial septal defect. In this case the former component is patent foramen ovale and the latter is the cyst above the heart and constrictive pericarditis. Constrictive pericarditis and the cyst above the heart can be a functional component of this syndrome but are rare in the literature. ${ }^{2,3}$ In this case two functional components coexisted, and it was of concern in regard to selection of treatments. To close the shunt, some reports recommend transcatheter occlusion because it is less invasive. ${ }^{1}$ In this case constrictive pericarditis might also contribute to the cause of this symptom, and therefore pericardiectomy was needed simultaneously. In addition, the pathology of the cyst was not unknown before treatment. These factors let us choose a surgical repair. The cyst was formed from the hematoma between a polytetrafluoroethylene sheet and the pericardium. One possible explanation why our patient presented with this symptom is that distortion of the right atrium and right ventricle by the cyst occurred, and as constrictive pericarditis was getting worse, he required high filling pressure to maintain an adequate cardiac output. ${ }^{4}$ With the patient in the upright position, the right ventricular preload diminished, resulting in decreased right-sided cardiac

*Gore Preclude, registered trademark of W. L. Gore \& Associates, Inc, Newark, Del. 


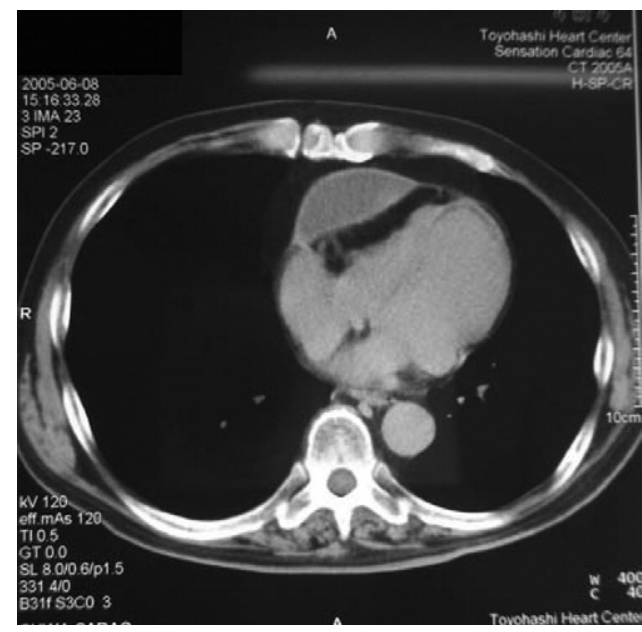

Figure 1. Preoperative computed tomography revealed an abnormal cyst above the heart. The cyst compressed the right atrium and right ventricular outflow.

output. As a result, there would be an increase in V/Q mismatch in zone I pulmonary circulation and increased dyspnea.

Although there is a high incidence of patent foramen ovale in the general population (ie, autopsy studies indicate an incidence of $27 \%$ ), this kind of complication after surgical intervention is occurring more frequently but is not being recognized because of a lack of awareness. ${ }^{5}$ The patient has a history of multiple cerebral
TABLE 1. Cardiac catheterization parameters (supine)

\begin{tabular}{lcc}
\hline & Pressure, mm Hg (mean) & 0ximetry (\%) \\
\hline RA & $(5)$ & 73.9 \\
PA & $13 / 6(9)$ & 75.6 \\
PCW & $(5)$ & \\
LV & $70 /$ edp 8 & 95.4 \\
LA & $(7)$ & 86.2 \\
Ao & $70 / 54(61)$ & 92.8 \\
\hline
\end{tabular}

$R A$, Right atrium; $P A$, pulmonary artery; $P C W$, pulmonary capillary wedge; $L V$, left ventricle; $e d p$, end-diastolic pressure; $L A$, left atrium; $A o$, aorta.

infarctions and the characteristic pattern of occurrence of dyspnea, and these suggested this syndrome. It is important to note the pattern of occurrence of dyspnea for accurate diagnosis.

\section{References}

1. Cheng TO. Platypnea-orthodeoxia syndrome: etiology, differential diagnosis, and management. Catheter Cardiovasc Interv. 1999;47:64-6.

2. Mashman WE, Silverman ME. Platypnea related to constrictive pericarditis. Chest. 1994;105:636-7.

3. Miller DC, Ricks W, Oyer PE, Cipriano PR, Shumway NE. Localized tamponade of the right atrium and right ventricle: Induction of intracardiac right-to-left shunting after the use of a Gott shunt. Arch Surg. 1978;113:764-6

4. Zanchetta M, Rigatelli G, Ho YS. A mystery featuring right-to-left shunting despite normal intracardiac pressure. Chest. 2005;128:9981002.

5. Hussain SF, Mekan SF. Platypnea-orthodeoxia: report of two cases and review of the literature. South Med J. 2004;97:657-62.

\section{Against the odds: Long-term outcome of drastic-risk cardiac surgery}

Serban Stoica, AFRCS, Hiremagalur Balaji, MRCS, Adel Helmy, MRCS, Jago Kitcat, BA, Carol Freeman, MSc, Linda Sharples, PhD, and Samer A. M. Nashef, FRCS, Cambridge, UK

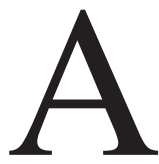

$\mathrm{n}$ average early mortality in low, single-percentage figures is now the norm in most cardiac surgical centers. Nevertheless, the spectrum of risk for individual patients is wide, and there are times when surgeons are called on to perform operations in patients in a precarious situation, for example, with associated comorbidity, an inherent

From the Papworth Hospital, Cambridge, United Kingdom.

Received for publication June 14, 2006; accepted for publication June 28, 2006.

Address for reprints: Samer A. N. Nashef, FRCS, Consultant Cardiothoracic Surgeon, Papworth Hospital, Papworth Everard, Cambridge CB3 8RE, UK

(E-mail: Sam.Nashef@ papworth.nhs.uk).

J Thorac Cardiovasc Surg 2006;132:1226-8

0022-5223/ $\$ 32.00$

Copyright $\odot 2006$ by The American Association for Thoracic Surgery doi:10.1016/j.jtcvs.2006.06.036 risk of complex surgery, or, commonly, both. Risk-assessment models can help identify high-risk patients who require cardiac surgery. Some studies report good results for patients who have a protracted stay in the intensive care unit because of perioperative problems, but the majority of such patients have an acceptable risk to start with. Little is known about the long-term outcomes of drastic-risk cardiac surgery. Are such high-risk, resource-intensive interventions worthwhile?

We sought to determine late survival and quality of life (QOL) in patients undergoing cardiac surgery with a predicted risk of death greater than $50 \%$ at the time of operation. Estimated mortality was calculated using the logistic EuroSCORE because of its good track record for accurately identifying high-risk cases. ${ }^{1}$

\section{Patients and Methods}

Ethical approval for the study was sought and obtained. Of 9971 consecutive patients who underwent cardiac surgery at Papworth Hospital between 1998 and 2004, 142 (1.4\%) had a logistic 